\title{
DEL ESTATUTO DE RADIO Y TELEVISIÓN A LA RUPTURA DEL MONOPOLIO: UNA MIRADA AL PANORAMA TELEVISIVO DE LOS AÑOS 90
}

\section{STATUTE OF RADIO AND TELEVISION TO THE BREAKUP OF MONOPOLY: A LOOK AT THE TELEVISION LANDSCAPE OF THE 90'S}

\section{AUTOR}

\section{Miguel Ángel Ortiz Sobrino}

Profesor Facultad de Ciencias de la Información de la Universidad Complutense de Madrid (España) maortiz@ccinf.ucm.es

\section{RESUMEN}

Televisión española se inauguró en Madrid el 19 de octubre de 1956, en un clima de hermetismo político, económico y cultural propio de la dictadura franquista. La petición de una televisión propia por parte de las distintas nacionalidades se hizo constante durante los años de la transición política. El referente general para amparar tal petición fue el artículo 20 de la constitución. En su apartado 3, se afirma que:

"la ley regulará la organización y el control parlamentario de los medios de comunicación social que dependan del Estado o de cualquier entidad pública, y garantizará el acceso a estos medios por 
parte de los grupos sociales y políticos significativos, respetando el pluralismo de la sociedad y de las diferentes lenguas de España".

Además, el propio Estatuto de RTVE establecía la concesión de un tercer Canal gestionado por cada comunidad autónoma.

La Ley de televisión privada se aprobó el 14 de marzo de 1988. La televisión quedó definida como un servicio público. Esta normativa hizo posible que sociedades mercantiles de titularidad privada tuvieran cabida en la gestión de dicho servicio. La ley limitaba a tres el número de concesiones, alegando cálculos de viabilidad económica y exigencias o limitaciones técnicas, además del interés público. La fragmentación de la audiencia cobró un nuevo impulso en 1990 con la implantación de los tres primeros canales de televisión privada - Antena 3, tele 5 y Canal Plus-. El mejor termómetro de la situación fue Televisión Española, que vio cómo la audiencia media de sus programas de mayor aceptación para del $50 \%$-en los últimos años de monopolio- al 30\% -últimos meses de 1990 y primero de 1991.El aumento del número de canales de televisión y de las horas de emisión no supuso, sin embargo, un crecimiento significativo del consumo de televisión.

\section{PALABRAS CLAVE}

Televisión - Inversión publicitaria, audiencias - Televisión pública -Televisión privada

\section{ABSTRACT}

Spanish television was inaugurated in Madrid on October 19, 1956, in a climate of secrecy political, economic and cultural characteristic of the Franco dictatorship. The request for a television of their own by the different nationalities was constant during the years of political transition. The general reference to cover such a request was Article 20 of the constitution. In paragraph 3, states that 
"the law shall regulate the organization and parliamentary control of the media that depend on the state or any public entity, and ensure access to these means by significant social and political groups, respecting the pluralism of society and the various languages of Spain".

In addition, the statute itself provided for the granting of RTVE a third channel managed by each region. Private Television Act was adopted on March 14, 1988. The television was defined as a public service. This legislation made it possible for privately held corporations have no place in the management of the service. La law limited to three the number of concessions, saying estimates of economic viability and technical requirements or limitations, as well as the public interest. The fragmentation of the audience gained a new momentum in 1990 with the introduction of the first three private television channels, Antena 3, Tele 5 and Canal Plus. The best barometer of the situation was Spanish TV, which saw its average audience for its programs widely accepted by $50 \%$, in recent years of monopoly, $30 \%$-final months of 1990 and first increase 1991.El number of television channels and broadcasting hours did not mean, however, a significant increase in television consumption.

\section{KEY WORDS}

Television advertising spend - Audiences - Public television - Private television

\section{ÍNDICE}

1. Claves para entender el entorno televisivo español.

2. La televisión privada.

3. Las inversiones publicitarias en televisión.

4. Bibliografía. 


\section{Claves para entender el entorno televisivo español}

\subsection{La crisis de la televisión pública}

Los primeros síntomas de que el modelo de la televisión pública entra en crisis se remontan a finales de los años setenta. Según recoge Pere Oriol-Costa en "la Crisis de la televisión pública", la empresa Promotora de Televisión Catalana S.A. emprendió en Barcelona una campaña de suscripción de acciones con el objetivo de crear un canal de televisión privada ${ }^{1}$. No obstante, el autor señala a la sociedad Antena 3 como principal protagonista de la ofensiva privatizadora en nuestro país, al solicitar en diciembre de 1978 un permiso para poner en funcionamiento una televisión de ámbito estatal. En el verano de 1981 llevó a cabo una campaña en la prensa escrita donde se daba por hecho la inmediata aprobación de la televisión privada. A esta campaña se añade el proceso judicial, dirigido por el profesor Jiménez de Parga, que protagonizó Antena 3 al solicitar el derecho de antena. Cuando se le denegó la petición, interpuso un recurso contencioso administrativo - en 1981- que fue también desestimado. Meses después, en agosto de 1981, Antena 3 presenta un recurso de amparo en el Tribunal Constitucional que es admitido a trámite. La sentencia se hizo pública en marzo de 1982 y admitió la constitucionalidad de la televisión privada, aunque matizaba que era al poder ejecutivo y al legislativo a quien correspondía regularla.

El triunfo del Partido Socialista Obrero español en las elecciones de 1982 supuso un aplazamiento para la aparición de las televisiones privadas. EI PSOE había anunciado el fortalecimiento de RTVE dentro de sus prioridades. El plan de actuación de José María Calviño, nuevo director nombrado por el gobierno de Felipe González, se marcó el objetivo de promover una televisión pública plural y profesional, a la vez que convertir al Ente Público en una verdadera empresa. Para ello plateó dedicar especial atención a las áreas técnicas y de finazas, se impuso el reto de reducir los

\footnotetext{
${ }^{1}$ ORIOL-COSTA, Pere (1986): La crisis de la televisión pública. Paidós Comunicación. Barcelona (págs. 324 y ss.)
} 
gastos de personal entre 800 y 1000 millones de pesetas al año, además de aumentar los ingresos entre 500 y 1000 millones de pesetas.

\subsection{El estatuto de RTVE}

Sin embargo, la televisión de esa época no se entiende sin el Estatuto de Radio y Televisión.

El Estatuto de Radio y Televisión fue aprobado por las cortes el 10 de enero de 1980. En él se declara servicios públicos esenciales a la radio y la televisión. Para ejercer este servicio se creó el Ente Público Radio televisión Española, donde se integran tres sociedades: TVE, RNE y Radiocadena española. Con el Estatuto se reserva la televisión al sector público y se prevé la concesión de un canal de televisión a las comunidades autónomas. El profesor Oriol-Costa entiende que esta concesión supuso "una ruptura controlada del monopolio televisivo".

El modelo televisivo promovido por el Ente Público era similar al vigente en la Europa occidental y significaba pasar de una televisión de corte dictatorial a otra de carácter democrático. El ejecutivo vio recortados sus poderes, ya que el Ente goza de autonomía y del control del Parlamento.

El Consejo de Administración, los Consejos Asesores, el Director general y los Delegados territoriales en las Comunidades Autónomas componen la estructura organizativa del Ente Público. El gobierno es el encargado de nombrar al director general. Su mandato es de cuatro años y no es compatible con un escaño parlamentario o con cualquier otro tipo de vinculación en empresas del sector. Al gobierno se encomienda también la asignación de frecuencias, el dictado de normas para el desarrollo del estatuto, previa consulta con el Consejo de Estado, además de la creación de sociedades filiales y fijar las horas de programación. 
Oriol-Costa vincula la historia de RTVE, desde la aprobación del estatuto hasta las elecciones de 1982, a los acontecimientos políticos vividos en España en ese período. Así, se refiere al golpe de estado del 23 de febrero como 2punto culminante" de la crisis política, con la ocupación de los golpistas de la televisión ${ }^{2}$.

"Sólo así se explica el retraso en un año de la puesta en práctica del Estatuto de RTVE con el nombramiento final de Fernando Castedo, un militante de la Unión de Centro Democrático (UCD), como director general. Su designación fue bien aceptada por la oposición de izquierdas." (ORIOL-COSTA, 1986, PÁG 328)

El estatuto se configuró como soporte legal sobre el que se realizó la fusión entre radio Nacional y Radiocadena Española.

\subsection{De la descentralización de TVE a las televisiones autonómicas.}

Televisión española se inauguró en Madrid el 19 de octubre de 1956, en un clima de hermetismo político, económico y cultural propio de la dictadura franquista.

El exceso de trabajo en los estudios de Madrid propició la apertura, en 1959, de los estudios de televisión en Barcelona, ubicados en el antiguo hotel Miramar. Miramar se diseñó como centro productor de programas para TVE y su instalación se realizó al margen de Cataluña y su cultura. Hasta 1964 TVE no transmite un programa en catalán. Durante la celebración de las fiestas de La Merced de Barcelona, se emitió una obra de teatro en catalán. A partir de entonces, se programa una pieza teatral en lengua catalana cada mes. A pesar de ello, TVE de Barcelona no emite un espacio mensual en catalán hasta 1967.

\footnotetext{
${ }^{2}$ ORIOL-COSTA, Pere (1986): La crisis de la televisión pública. Paidós Comunicación. Barcelona (pág, 328)
} 
En 1973 se programan dos musicales con María del Mar Bonet y Lluís Llach. Esta tendencia permisiva del régimen hacia la programación en catalán - tenía un carácter marginal, tanto por las horas de emisión como por la escasez de medios de producción- estuvo presente también en la apertura de nuevos centros de emisión en el País Vasco, Galicia, canarias y en otras ciudades del país. Oriol-Costa encuentra en esta expansión un "crecimiento de la televisión" más que "un plan o voluntad de descentralización". A partir de 1976, se potencia la información y la programación en todos los centros regionales.

La petición de una televisión propia por parte de las distintas nacionalidades se hizo constante durante los años de la transición política. El referente general para amparar tal petición fue el artículo 20 de la constitución. En su apartado 3, se afirma que...

"la ley regulará la organización y el control parlamentario de los medios de comunicación social que dependan del Estado o de cualquier entidad pública, y garantizará el acceso a estos medios por parte de los grupos sociales y políticos significativos, respetando el pluralismo de la sociedad y de las diferentes lenguas de España".

Además, el propio Estatuto de RTVE establecía la concesión de un tercer Canal gestionado por cada comunidad autónoma.

La Ley de Terceros canales se aprobó el 26 de diciembre de 1983. Con ella todas las comunidades autónomas adquirieron un marco legal para poder tener su propia televisión.

En esa fecha el canal vasco - Cuarto canal- emitía regularmente, mientras que el Tercer Canal de Cataluña empezaba a emitir en pruebas. En 1986, la televisión catalana emite ya su programación íntegramente en catalán. 
La Compañía de radiotelevisión de Galicia comenzó sus emisiones en prueba el 24 de julio de 1985, y desde entonces transmite una programación en gallego.

\subsection{Las televisiones autonómicas}

Las televisiones autonómicas eran un modelo nuevo no sólo en nuestro país, donde las más antiguas tienen poco más de diez años de vida, sino también dentro del ámbito europeo, donde no existían modelos de televisión similares.

El concepto de televisión autonómica venía avalado por su propio nombre y por las leyes que permitido su puesta en funcionamiento; que establecen sus competencias, su forma de financiación y su espacio de cobertura.

Las televisiones autonómicas dependen exclusivamente de las instituciones de poder público de cada comunidad autónoma. Además, esa autonomía va más allá: no dependen de otros sistemas de televisión públicos para difundir sus programas. También disponen de total autonomía para asignarse recursos económicos para determinar las horas diarias de emisión, y para diseñar sus parrillas de programación y las retransmisiones que desean realizar.

Las televisiones autonómicas fueron las primeras competidoras de RTVE. El 31 de diciembre de 1982, Euskal Telebista rompía no sólo el monopolio, sino también un modelo de televisión que hasta entonces no tenía competencia. Desde esa fecha, y por orden cronológico de aparición, la configuración del mapa de las televisiones autonómicas en España abrió, con uno o dos canales, a seis comunidades autónomas: País Vasco, Cataluña, Galicia, Andalucía Madrid y Valencia. Este era el panorama que se perfilaba en 1989. 


\subsection{El ordenamiento legal de las Televisiones Autonómicas}

Los primeros textos legales que aparecen en España tipificando las televisiones autonómicas fueron los estatutos de autonomía del País Vasco y de Cataluña, publicados como leyes orgánicas del Estado en el BOE del día 22 de diciembre de 1979. A los pocos días, el 12 de enero de 1980, el BOE publicó la Ley del Estatuto de radio y televisión, en la que afirmaba que el Gobierno podrá conceder a las comunidades, previa autorización de las Cortes generales, la gestión directa de un canal de televisión de titularidad estatal que se cree específicamente para el ámbito territorial de cada comunidad autónoma. Sin embargo, como recoge Arturo Maneiro ${ }^{3}$,

"la ley citada no entró en vigor hasta después de cuatro años, en enero de 1984. Cuanto esto sucedió, el País vasco y Cataluña ya habian puesto a funcionar su propia televisión, dentro de un proceso de enfrentamientos constantes entre la Administración central, las autonomías y el Ente RTVE para intentar delimitar las competencias de cada institución". (Maneiro Vila, 1990/91, Pág 152)

Desde 1982 hasta 1989 se aprobaron 11 leyes de constitución de otras tantas compañías de radio y televisión autonómicas, como paso previo a la puesta en marcha de estos medios de comunicación. Sin embargo, tan sólo seis comunidades autónomas han llegado a crear sus correspondientes televisiones, con uno o dos canales, tal y como se recoge en el siguiente cuadro.

\subsection{La función social de las Televisiones Autonómicas}

En todas las leyes de creación de las televisiones autonómicas se establecen una serie de principios generales y su ámbito de aplicación. En el caso de las

\footnotetext{
${ }^{3}$ MANEIRO VILA, Arturo: "Las televisiones autonómicas en España". En Revista Situación 1990/91. Servicio de estudios del banco Bilbao-Vizcaya. (Pág. 152).
} 
comunidades autónomas con idioma propio, se marca como uno de los objetivos primordiales la promoción de la cultura y de su lengua. También se establece el respeto a los principios de igualdad, al pluralismo político, religioso y social, y la defensa de los valores cívicos de la convivencia, recogidos en la Constitución y en los estatutos de autonomía en defensa del interés general.

En el caso de las comunidades sin idioma propio, los principios generales son los mismos, aunque el apartado relativo a la lengua señala "la promoción de los valores históricos, culturales, educativos y lingüisticos en toda su riqueza y variedad". 8Ley8/1987 de 9 de diciembre, de creación de la empresa pública de la radio y la televisión de Andalucía.)

De las seis televisiones autonómicas existentes a finales de 1989, cuatro de ellas emitían en lengua propia: País Vasco, Cataluña, Galicia y Valencia. Las otras dos, Canal Sur y Telemadrid, lo hacían en castellano.

\subsection{Audiencia de las Televisiones Autonómicas}

A mediados de 1989, las televisiones autonómicas acumulaban una audiencia total de 6.200.000 telespectadores, según los datos del EGM relativos a los meses de mayo junio. Las audiencias indicaban hasta qué punto existía una base sobre la que aplicar la función social que tiene encomendada cada televisión autonómica. Aunque Arturo Maneiro ${ }^{4}$ asegura que

"el objetivo casi exclusivo de las mediciones de audiencia es la captación de publicidad, que genera unos ingresos económicos destinados a disminuir la dependencia de las televisiones

\footnotetext{
4 MANEIRO VILA, Arturo: “Las televisiones autonómicas en España”. En Revista Situación 1990/91. Servicio de estudios del banco Bilbao-Vizcaya. (pág. 157).
} 
autonómicas de los presupuestos públicos de la respectiva comunidad autonómica". (Maneiro Vila, 1990/91, Pág 157)

Los niveles de audiencia mostraban importantes diferencias dependiendo de las televisiones. Según el informe de Fundesco ${ }^{5}$, durante 1989

"no sólo se asistió al nacimiento de las nuevas emisoras- Andalucía, Madrid, Valencia y una segunda en Cataluña-, sino también al fortalecimiento de una audiencia autonómica específica, con repercusión directa en los niveles máximos de audiencia de TVE'. (Diaz Nosty, 1990, Pág 41 - 42)

En el informe se incluía la evaluación del EGM correspondiente a octubre-noviembre de 1989. De acuerdo con estos datos, la televisión catalana TV-3 tenía en su ámbito el 47,1\% de la audiencia: El Canal Sur andaluz, el 45,9\%, y la cadena gallega TVGA, el $43,4 \%$, con lo que se situaban en los puestos de cabeza entre las emisoras autonómicas. Las cadenas vascas ETB1 (en euskera) y ETB2 (en castellano), con el $33,9 \%$, y las recién nacidas TVV (Canal Nou) -33\%-. Telemadrid -26,1\% - y canal 33, con el 5,5\%, cerraban el esqueleto de la audiencia.

La estimación de la Agencia Clarín, incluida también en este informe, concluía que...

"el asentamiento de los terceros canales públicos, todos ellos deficitarios, con excepción del catalán TV-3, iba a suponer, para 1990, que el conjunto de las emisoras autonómicas alcanzaran una cuota de mercado del 18\%, muy por encima de las cifras previstas para el primer año de las televisiones privadas, que reducían al 6\%".

(...)

\footnotetext{
${ }^{5}$ DIAZ NOSTY, Bernardo. 'Nuevo mosaico audiovisual'. En VV.AA. Comunicación Social: 1990. Tendencias. Funesco. Madrid (págs. 41 y 42)
} 
De esta forma, comenzaban a verse los primeros impactos en la segmentación de la audiencia que incidiría, lógicamente, en la radio del país.

\subsection{La incidencia económica de la Televisión autonómica en las regiones y autonomías.}

La creación de una televisión autonómica generó en su ámbito de influencia la aparición de empresas auxiliares de servicios, así como la de puestos de trabajo en el sector audiovisual. Los impulsos de los canales autonómicos supusieron, además, una potenciación de las actividades artísticas, culturales e intelectuales en las respectivas comunidades autonómicas.

Arturo Maneiro ${ }^{6}$ afirma que las televisiones autonómicas TV3, ETB y TVGA deban trabajo en 1989 a un total de 2025 personas, teniendo en cuenta su actividad directa. En las otras televisiones que comenzaron en 1989 se preveía emplear a otras 930 personas.

En cuanto a las industrias auxiliares, las principales por el volumen de facturación y producción eras las productoras de video y cine, y los estudios de doblaje de películas al idioma de las televisiones autonómicas que lo necesitasen. Manerio sostiene que

"el comienzo de las emisiones de la televisión gallega y de ETB hizo necesaria la creación de este tipo de empresas, puesto que no había mercado ni en Galicia ni en el País Vasco. Sin embargo, Cataluña contaba ya con una industria fuerte en este sector y no fue necesario crearla con la aparición de TV3" (Maneiro Vila, 1990/91, Pág 158)

\footnotetext{
6 MANEIRO VILA, Arturo: “Las televisiones autonómicas en España”. En Revista Situación 1990/91. Servicio de estudios del banco Bilbao-Vizcaya. (pág. 158)
} 


\subsection{La financiación de la Televisiones Autonómicas}

La instalación, puesta en funcionamiento y explotación de las seis televisiones autonómicas había costado, hasta 1989, cerca de 125500 millones de pesetas. Los ingresos generados por publicidad se aproximaron a los 40000 millones de pesetas, sin contar los ingresos de 2000 millones previstos por Canal Sur para el ejercicio de 1989. Así lo detalla Arturo Maneiro ${ }^{7}$, quien afirma que estos resultados supusieron una autofinanciación media del 33,5\%.

"Sin embargo, la TV 3 catalana está muy por encima de la media, ya que en los dos últimos años alcanzó una autofinanciación por publicidad y venta de programas del $66 \%$, en 1988 , y del $82 \%$, en 1989. Estas cifras demuestran que las televisiones autonómicas seguirán dependiendo de la subvenciones públicas que en cada comunidad autoricen sus respectivos parlamentos y ejecutivos". (Maneiro Vila, 1990/91, Pág 159 - 160)

Atendiendo a los datos incluidos en el informe de Fundesco relativo a $1989^{8}$, el presupuesto de Canal Sur era en ese ejercicio de 8100 millones de pesetas. El de TV3, de 9000 millones, al igual que el de ETB. La televisión gallega tenía un presupuesto de 6500 millones de pesetas; Telemadrid, de 4000 millones, y la televisión valenciana otros 4000 millones de pesetas. La única televisión autonómica que se autofinancia desde 1987 era, según este informe, la catalana Tv-3, que en 1989 no tuvo asignación tributaria de la Generalitat.

\footnotetext{
7 MANEIRO VILA, Arturo: “Las televisiones autonómicas en España”. En Revista Situación 1990/91. Servicio de estudios del banco Bilbao-Vizcaya. (pág. 159 y 160)

8 DIAZ NOSTY, Bernardo. “Espacio autonómico audiovisual”. En VV.AA. Comunicación Social 1989. Tendencias. Fundesco. Madrid. (pág. 42).
} 
Los altos porcentajes de dependencia de las subvenciones del sector público hacían que los responsables de las televisiones autonómicas centraran sus esfuerzos en conseguir mayores ingresos por publicidad a base de promociones comerciales de alcance nacional, no sólo a los anunciantes de la comunidad autónoma. Las promociones de bloques publicitarios de contratación de publicidad a empresas del sector que le garantizaran unos determinados ingresos durante un período acordado. Por ejemplo, ETB firmó en 1988 un contrato con el holding Berlusconi a través de la empresa Fininvest. La televisión gallega suscribió un contrato semejante para el período 1990-93 por una cifra mínima de 10000 millones de pesetas.

Los problemas de financiación para el sector público de radio y televisión empezaban a aflorar.

\section{La televisión privada}

El final de la década de los ochenta marcó el inicio de la televisión privada en España.

\subsection{La televisión por cable}

La televisión por cable era, en aquella época, uno da las iniciativas de la televisión privada que, según sus promotores, fue consecuencia de la necesidad de ver una televisión distinta de la estatal o autonómica. A pesar de que la televisión por cable no había funcionado de forma regular en nuestro país, la extensión de las redes de cable amplió la posibilidad de recibir más programas de televisión. 
Esteban Escobar y Luis Ángel de la Viuda ${ }^{9}$ sitúan en el municipio barcelonés de Vilada la primera red de cable instalada en España. Los vecinos de Vilada necesitaban de un repetidor para ver la Segunda Cadena de TVE, según cuentan ambos autores. La red de cable les permitió recibir los dos canales de la televisión estatal, la señal de TV 3 y una serie de canales procedentes del satélite, además de una escueta programación local. Este tipo de experiencias se fue extendiendo de manera confusa, sin llegar a distinguirse muy bien del vídeo comunitario.

Uno de los proyectos más ambiciosos de la incipiente televisión por cable fue el suscrito en 1972 entre la Compañía telefónica Nacional de España (CTNE), la Dirección General de Radiodifusión y TVE. El objetivo inicial de este proyecto era crear una red de cable en Madrid y en Barcelona capaz de distribuir nueve canales de televisión distintos. Ambas redes - propiedad de Telefónica y xon derecho de explotación exclusiva de RTVE durante diez años- estaba previsto que se implantaran en una superficie de $8 \mathrm{~km}$., con distribución de programas por VHF y capacidad para 72000 abonados.

La red era unidireccional y estaba construida con cable coaxial. Se tendió en zonas de Madrid y Barcelona con importantes índices de densidad de población y de poder adquisitivo: en la calle Rosales, El Paseo de la Castellana y los barrios de Salamanca y Retiro, en Madrid, y en las zonas del centro de la Ciudad Condal, Ensanche, Pedralbes y General Goded.

La sede de la televisión se ubicó en Madrid, en los antiguos estudios del Paseo de la Habana, desde donde estaba previsto emitir dos programas. Aunque las pruebas de señal fueron positivas, todo quedó en un proyecto. Pero Oriol-Costa ${ }^{10}$ atribuye el

\footnotetext{
${ }^{9}$ LÓPEZ ESCOBAR, Esteban y DE LA VIUDA, Luis Ángel: "La televisión no pública". En Revista Situación 1990/91. Servicios de estudios del BBV. (pág. 175).

${ }^{10}$ ORIOL-COSTA, Pere. La crisis de la televisión pública. Paidós Comunicación. Barcelona 1986. (pág. 335)
} 
fracaso de esta iniciativa a que "el interés primordial de los promotores se centraba en la obtención de beneficios". (Oriol-Costa, 1986, Pág 328)

A finales de 1988, CAMBIO 16 publicaba un informe en el que se describía el vídeo comunitario/televisivo por cable como un fenómeno fundamentalmente andaluz. A excepción de J aén y Málaga, el resto de provincias contaban con 60000 abonados.

Procono S.L. (promociones Comerciales Novedosas) era una de las empresas más prolíficas en este sector televisivo. Contaba con redes en Córdoba, Málaga, Sevilla, Valencia, Madrid y Barcelona. Teleelx, de Elche Comunicaciones S.A., era otra de las sociedades más conocidas. En 1989 declaraba tener 18000 abonados.

El número de empresas que operaba en el sector del vídeo comunitario/televisivo por cable se situaba en las 700 en 1989, según un informe de la asociación Española de empresas de Video Comunitario (AVIDECO) y Broadcast televisión Video (BTV) Europa S.A.

En el informe se asegura que 560 empresas estaban registradas y que las otras 140 eran "incontroladas". El número de abonados calculados era de 1.500 .000 y el de espectadores 525.0000. La red le costaba a cada abonado entre 2.000 y 25.000 pesetas, siendo la media mensual de pago para el abonado mil pesetas y el precio de conexión a la red de 6.000 a 7.000 pesetas. El citado informe detalla que un spot publicitario de 20 segundos, en una red de 5.000 a 6.000 abonados, costaba entre 4.000 y 50.000 pesetas.

\subsection{El Canal 10}

El 3 de noviembre de 1987, la Cadena Ser anunciaba la creación de canal 10, una sociedad que quería implantar canales privados de televisión emitiendo por satélite 
desde Londres J.R: Pérez Ornia ${ }^{11}$ observaba la coincidencia de este anuncio con la crisis de los vídeos comunitarios en nuestro país, y destacaba que

"los bajos costes de los vídeos comunitarios permitieron negocios muy rentables para una audiencia próxima a los dos millones de telespectadores, tanto como quería conseguir Canal 10". (Pérez Ornia, 1988, Pág 206)

Dos leyes, la Ley de propiedad Intelectual, publicada el 11 de diciembre de 1987, y la Ley de Ordenación de las telecomunicaciones (LOT), de diciembre de ese año, beneficiarían -según reflexión de Pérez Ornia- indirectamente al proyecto de canal 10. La primera porque obligaba a los vídeos comunitarios a pagar los derechos de autor; y la segunda, porque situaba en la ilegalidad a los vídeos comunitarios cuyos tendidos de cable cruzaban espacios públicos.

Canal 10 se presentó como un canal de pago -3000 pesetas al mes- $y$, en principio, sin publicidad ni servicios informativos. La programación se basaba en las películas, series de televisión y de dibujos animados.

La sociedad se constituyó con un capital de 1000 millones de pesetas. El empresario Enrique Talarewitz, que tenía la distribución de Warner Bross en España, era el accionista mayoritario con el $41 \%$ de las acciones. El resto se repartía entre dos bancos, Canal Plus Francia, la sociedad Noara -integrada por un grupo de empresarios vascos- . el empresario Jacques Hachuel y la Compañía de radio y televisión de Luxemburgo.

En una primera etapa estaba previsto cubrir los mercados de Madrid, Barcelona, Valencia y Bilbao; y en la segunda, los de Sevilla, Zaragoza, Málaga, Oviedo, Gijón y

\footnotetext{
${ }^{11}$ PÉREZ ORNIA, José ramón. “Más televisión” en Anuario El País 1988. Ediciones El País. (pág. 206).
} 
Avilés. En pocos meses canal 10 pretendía contar con 350000 abonados e instalas 1600 antenas.

Las emisiones de canal 10 empezaron en enero de 1988 con una programación sin codificar de cuatro horas distintas. A finales de agosto se suspendían. Los estudios londinenses se negaron a prestar sus servicios hasta que no se pagara el alquiler de los últimos meses. Además de los problemas de pago, desde el principio hubo enfrentamientos entre los accionistas, a la vez que cambios en la titularidad de las acciones.

López escobar y Luis ángel de la Viuda" relatan "la aventura del Canal 10" con todo detalle:

" el que fue el primer canal comercial español acabó en los tribunales, con sus socios planeando un relanzamiento del canal para el que se anunciaba una inversión de 5.000 millones... En la última decena de octubre, canal Plus abandonó la aventura de Canal 10 y anunció su propósito de presentarse al concurso para obtener una de las tres cadenas de televisión nacional, después de declarar una pérdida de 700 millones de pesetas." (López Escobar, De La Viuda, 1990/91, Pág 180)

\subsection{La televisión por satélite}

La televisión por satélite fue otra de las iniciativas de la televisión no pública sobre la que planeaban grandes perspectivas de expansión y desarrollo. Las informaciones sobre el parque de antenas en nuestro país eran poco sólidas y demasiado optimistas cuando procedían de empresas del sector.

\footnotetext{
12 LÓPEZ ESCOBAR, Esteban y DE LA VIUDA, Luis Ángel: "La televisión no pública" en Revista Situación 1990/91. Servicios de estudios del BBV ( pág. 180).
} 
Televés, la empresa líder en el sector, afirmaba en 1989 que el parque de antenas superaba los 20000 instalaciones. El crecimiento previsto para ese año era del $100 \%$ en sistemas colectivos y del $50 \%$ en los individuales.

Galavisión, el canal vinculado al Grupo Televisa, comenzó su expansión en España. En 1990, el número de telespectadores que lo habían sintonizado era de 83106, según informaciones de Galavisión. El parque de antenas de las 10 ciudades más importantes del país lo cifraba en un total de 8676. Su distribución era irregular: en Madrid más de 3600 y en Barcelona cerca de 1000.

López escobar y Luis ángel de la Viuda ${ }^{13}$ rescatan un informe publicitario de Galavisión donde se asegura que 2200000 telespectadores sintonizaban sus programas, de los que 1250000 lo hacía a través de antena parabólica y otros 950000 mediante vídeo comunitario.

Al margen de estas experiencias, las expectativas estaban puestas en el satélite español Hispasat, con el que se ampliarían los canales de televisión, se mejorarían las comunicaciones telefónicas, así como la transmisión de datos informáticos.

En enero de 1990, el Consejo de Ministros decidió adjudicas la fabricación del Hispasat a la empresa francesa Matra. Poco después otorgó el lanzamiento a Arianespace.

El Hispasat supuso un avance respecto a los satélites de telecomunicación que había en 1990. Según reseña José $\mathrm{F}$. Beaumont ${ }^{14}$, entre sus funciones destacaba la difusión directa de televisión, con cinco canales capaces de llevar señales de televisión de alta definición.

\footnotetext{
13 LÓPEZ ESCOBAR, Esteban y DE LA VIUDA, Luis Ángel: "La televisión no pública" en Revista Situación 1990/91. Servicios de estudios del BBV (pág. 186).

${ }^{14}$ BEAUMONT, J osé F. “La cuenta atrás del satélite Hispasat” en Anuario El País 1991. Ediciones el País. (pág. 164).
} 


\subsection{La televisión privada por vía hertziana}

La Ley de televisión privada se aprobó el 14 de marzo de 1988. La televisión quedó definida como un servicio público. Esta normativa hizo posible que sociedades mercantiles de titularidad privada tuvieran cabida en la gestión de dicho servicio.

La ley limitaba a tres el número de concesiones, alegando cálculos de viabilidad económica y exigencias o limitaciones técnicas, además del interés público de una programación diversificada.

La Ley obligaba a las sociedades concesionarias a emitir un mínimo de cuatro horas diarias y 32 semanales. Establecía unos porcentajes mínimos y compatibles de producción. Así, el 15\% debía ser de producción propia; el 55\% de la programación emitida sería en lengua española; el $40 \%$ de la producción, originaria en países integrantes de las Comunidades europeas, y el $40 \%$ de las películas emitidas en la programación mensual debería ser de producción originaria en los países de las Comunidades europeas.

La emisión de publicidad no podía superar el $10 \%$ del total de horas de programación anual, y se limitaba a 10 minutos el máximo de emisión publicitaria por hora.

\subsection{Las concesiones de las televisiones privadas}

El 25 de agosto de 1989 el gobierno hizo pública la concesión de los tres primero canales de televisión privada a Antena 3 Televisión, tele 5 y canal Plus. Después de 33 años, el monopolio de TVE se quebró. Los socialistas dieron luz verde a la televisión privada tras ocho años de discusiones políticas y jurídicas. En el camino se quedaron el proyecto de Univisión, del Grupo Zeta y del magnate australiano Robert Murdoch; Canal C, promovido por un grupo de profesionales y pequeños 
empresarios; y el canal auspiciado por el Grupo 16, que presentó la solicitud fuera del plazo establecido.

Al conocerse el resultado de la adjudicación, el presidente del grupo Zeta y la sociedad Univisión anunció un recurso de la decisión gubernamental. Sus argumentos eran que la concesión de Canal Plus no se ajustaba a la idea de un servicio abierto a todo público, ya que se trataba de una televisión de pago, y en que la concesión de Tele 5 se hacía a un grupo en el que participaba la ONCE que es una sociedad con un tratamiento fiscal diferente y cuyo presupuesto depende del Gobierno en último término.

J.F. Beaumont ${ }^{15}$ daba cuenta de los primeros problemas que debían afrontar los recién nacidos canales privados.

"Las televisiones privadas tienen que competir con los canales públicos de ámbito nacional - con programas regionales-, con siete canales autonómicos que se reparten el pastel publicitario, además de las principales producciones deportivas que se van a desarrollas. Del lado técnico, se encuentran con que la red de transmisión de señales es insuficiente y no van a poder llegar a todo el territorio nacional hasta que la transmisión no se haga por satélite. Ya sea mediante el alquiler a Retevisión o por medio del Hispasat, en 1992" (Beaumont, 1990, Pág 202)

El 15 de diciembre de 1989 Retevisión ofrecía las castas de ajuste de los tres nuevos canales. Antena 3 fue la primera en emitir en pruebas -el 25 de diciembre-, aunque las emisiones definitivas no se hicieron hasta un mes después. Antena 3 televisión, con el $25 \%$ del capital en manos del grupo Godó, diseñó una programación dirigida a

${ }^{15}$ BEAUMONT, José F. “La batalla de la televisión privada” en Anuario El País 1990. Ediciones El País (Pág. 202). 
lograr ingresos publicitarios, los informativos, las películas, los deportes y los debates iban a ser sus bazas fundamentales.

Tele 5 fue la segunda cadena en entrar en servicio. Lo hizo el 3 de marzo de 1990. Muy pronto tuvo que enfrentarse a un golpe de timón en su accionariado. El Grupo Anaya, con el 255 del capital, fue sustituido de la presidencia de la sociedad gracias a un pacto entre el empresario italiano Silvio Berlusconi y la ONCE, ambos con otro $25 \%$ de las acciones.

Canal Plus empezó a funcionar en septiembre de 1990 y ofreció parte de su programación codificada. Esta es la razón de que la mayoría de sus ingresos proceda de sus abonados y no de la publicidad como en el caso de Antena 3 y Tele 5 . El grupo PRISA, que tenía el 255 del capital, fue el impulsor del proyecto Canal Plus en España, siguiendo el modelo del Canal Plus Francia, que además poseía otro $25 \%$ de las acciones.

A finales de 1990, los canales privados podían ser vistos por la mitad de las población española -20 millones de personas-. Para el primer trimestre de 1991 se estimaba que la cobertura de telespectadores se ampliará en 1,3 millones de personas más-

Con las televisiones privadas llegó "la guerra de las programaciones $y$ contraprogramaciones" en las horas de máxima audiencia, básicamente por la pérdida de espectadores de algunos programas de Televisión Española. 


\section{3.- Las inversiones publicitarias en televisión}

A principio de la década de los ochenta, Roy Megary ${ }^{16}$, editor del Toronto Globe and Mail, auguraba que...

"hacia 1990, los editores de los grandes diarios dejaría de engañarse con la falsedad de que están en el negocio periodístico y admitirían, ante todo, que su verdadero negocio es transmitir mensajes publicitarios" (Diaz Nosty, 1990, Pág 65).

Esta tajante reflexión viene a aceptar que los beneficios de las empresas informativas están vinculados a la afluencia de publicidad, de la que va a depender en buena parte la economía de los medios de comunicación.

Acertó Megary. En 1990 más del 75\% de los ingresos de los diarios procedían de la publicidad, mientras que la radio y la televisión comercial vivían exclusivamente de la inversión publicitaria.

Seguros ya de la importancia de las inversiones publicitarias, hay que significar el singular papel de los anunciantes en los medios de comunicación, puesto que deciden en cuáles se invierte, y también el de los sistemas de medición de la audiencia. Tanto es así, que el estudio de la audiencia sobre muestras definitivas en ámbitos territoriales y en segmentos económicos es una exigencia de los anunciantes para conocer la rentabilidad de sus inversiones. En este contexto se sitúa la competencia de los medios de comunicación - prensa, radio y televisión- por conseguir un buen pedazo del denominado pastel publicitario.

\footnotetext{
16 DIAZ NOSTY, Bernardo. “La millonaria seducción del espectáculo" en VV.AA. (1990): Comunicación social: Tendencias. Fundesco. Madrid (Pág. 65)
} 
Los programas son el reclamo de la audiencia en el caso de la televisión y de la radio, así, los cambios de programación pueden ocasionar modificaciones en la orientación de la audiencia. En el análisis de tendencias realizado por Fundesco en $1989^{17}$ se exponían algunas diferencias entre los medios para captar audiencia. Según el informe, "la televisión no genera adhesiones tan marcadas como la prensa, ya que una de las características del medio audiovisual es la posibilidad de elegir una oferta variada y competitiva". (Diaz Nosty, 1989, Pág 70 -71)

Durante el período referido en este trabajo se amplía la oferta televisiva. Aparecen nuevas televisiones autonómicas y los canales privados. La competencia entre las televisiones se hizo posible tras los años de monopolio de televisión española. Al final, la cantidad no supuso una mejora de la calidad media de las programaciones. Eduardo Madinaveitia ${ }^{18}$ asegura que las posibilidades de elección de los espectadores tampoco se vieron favorecidas con la nueva situación, "ya que, como ocurría en la radio, se tiende a utilizar esquemas de programación muy similares, que terminan conduciendo al "más de lo mismo a las mismas horas". (Madinaveitia, 1991, Pág 54)

En 1989 los medios escritos figuraban a la cabeza de las inversiones publicitarias, con 349500 millones de pesetas, y obtenían el mayor crecimiento entre los medios de comunicación al aumentar un $27 \%$ en relación al año anterior. En el caso de los periódicos diarios. La inversión se incrementó en un $28,5 \%$, y en un $23,7 \%$ en el caso de las revistas.

Las inversiones en televisión no alcanzaron el crecimiento previsto, con 194000 millones de pesetas de ingresos por publicidad, experimentaron un incremento del

\footnotetext{
17 DIAZ-NOSTY, Bernardo. "La publicidad en el centro de la comunicación" en VV.AA. (1989): Comunicación Social: Tendencias. Fundesco (Pág. 70 y 71).

18 MADINAVEITIA, Eduardo. "Tendencias en medios audiovisuales" en VV.AA. (1991): Comunicación Social: Tendencias. Fundesco. Madrid (Pág. 54).
} 
19,7\%, cifra que situaba las inversiones en el año de la televisión matinal (TVE) a unos cinco puntos porcentuales por debajo de las previsiones.

La radio tuvo un crecimiento prácticamente similar - del 19,8\% - al ingresar 72200 millones de pesetas en concepto de publicidad.

\subsection{Publicidad y fragmentación de audiencias}

La aparición en 1989 de nuevas cadenas de televisión autonómicas supuso un gran cambio en las campañas publicitarias. Los anunciantes españoles mostraban su preocupación por la fragmentación de la audiencia televisiva, que se segmentaba por preferencias de programación y no en estratos diferenciados por su capacidad de compra. A su vez, la competencia entre cadenas por captar audiencia propia propiciaba que el espectador optara por el programa que más le gustaba en lugar de ser fiel a una televisión en concreto. Esta fragmentación de la audiencia se vería reflejada en la estrategia de los anunciantes, que tuvieron que ampliar sus inversiones para conseguir los niveles de audiencia que antes ofrecía la televisión estatal. También propició que los estudios de audiencia afinaran, puesto que la nueva situación obligaba a escrutar el comportamiento de los telespectadores al milímetro, para que las agencias de publicidad pudieran encontrar al consumidor allí donde se encontrara.

Ante el nuevo mapa televisivo se estimaba un aumento del porcentaje publicitario invertido en la televisión en detrimento de otros medios, especialmente de la radio y las revistas, y en menor medida en los periódicos. Sin embargo, entre 1989 y 1990, la cuota de la televisión descendió del 405 al 36\%, cuatro puntos porcentuales, los mismos que subieron conjuntamente los diarios, suplementos semanales y revistas, según datos de la federación Nacional de Empresas de Publicidad. Años después, la 
revista Noticias de la Comunicación analizaba esta circunstancia ${ }^{19}$. En un editorial de 1993, interpretó que el desplazamiento de la inversión publicitaria - de televisión a prensa- "parece responder a un exceso de oferta de espacios en las televisiones y a un abaratamiento de tarifas reales en las nuevas cadenas, que se traduce en una menos cuota". (VV.AA., 1993, Pág 3)

Hay que aclarar que la rebaja de las tarifas se produce en la práctica y de forma oficiosa, puesto que los precios suben en la mayoría de los casos.

En el citado editorial se destacaba el desvió que se producía entra las cifras de inversión

$$
\begin{aligned}
& \text { "controlada o estimada y la facturación real de los medios a } \\
& \text { consecuencia del endurecimiento del mercado publicitario, sumido en } \\
& \text { una guerra de descuentos, bonificaciones y compensaciones por la } \\
& \text { captura del cliente". (VV.AA., 1993, Pág 3) }
\end{aligned}
$$

La fragmentación de la audiencia cobró un nuevo impulso en 1990 con la implantación de los tres primeros canales de televisión privada -Antena 3, tele 5 y Canal Plus-. El mejor termómetro de la situación fue Televisión Española, que vio cómo la audiencia media de sus programas de mayor aceptación para del 50\% -en los últimos años de monopolio- al 30\% -últimos meses de 1990 y primero de 1991. El aumento del número de canales de televisión y de las horas de emisión no supuso, sin embargo, un crecimiento significativo del consumo de televisión. Fundesco recogía en un informe ${ }^{20}$ que durante 1990 la media diaria de permanencia ante el

\footnotetext{
${ }^{19}$ VV.AA. "La televisión defiende su trozo de tarta" en Noticias de la Comunicación. Publicaciones Profesionales no 93, 10/16 de mayo de 1993 (Pág. 3).

20 DIAZ NOSTY, Bernardo. "Televisión: la pobre pluralidad del espectáculo" en VV.AA. (1991) Comunicación social: Tendencias. Fundesco. Madrid. (pág. 51).
} 
televisor era de 184 minutos por persona, un 5,7\% más que el año anterior, que fue de 174 minutos.

De acuerdo con los datos de la empresa j. Walter Thompson (JWT), en 1990 sólo la televisión y la prensa diaria registraron crecimientos en la inversión publicitaria respecto a 1989. El aumento se cifró en el 5,3\% en el caso de la televisión, y en el $0,1 \%$ en la prensa diaria. La radio y las revistas, por el contrario, sufrieron una importante desaceleración, con descensos del $8,3 \%$ y del $11,1 \%$, respectivamente.

Por lo que se refiere a las cuotas de participación en el mercado publicitario, la prensa diaria, con el $39,8 \%$, consiguió el porcentaje más elevado de la última década. Las revistas, con el $16,4 \%$, se situaban en el nivel más bajo; al igual que la radio, que colocaba su cuota de participación en el 10,7\%. La televisión, con el $33,1 \%$, logró mejorar el buen resultado obtenido dos años antes.

Durante 1990 todas las cadenas autonómicas aumentaros sus ingresos publicitarios y con un volumen global de facturación muy superior al de los canales privados, que habían comenzado sus emisiones ese mismo año. Las previsiones de las autonómicas para 1991 era llegar a financiar el 58\% de su presupuesto vía ingresos publicitarios. El déficit estimado ascendía a 34343 millones de pesetas.

En el caso de Televisión Española, el pronóstico era que sus ingresos le permitieran financiarse, siempre y cuando no se incluyesen los presupuestos de RNE -28467 millones- ni los del Canal Internacional de Televisión, que eran de 10000 millones de pesetas en 1991. El presupuesto de TVE para 1991 se elevaba a 144917 millones de pesetas. Los ingresos por publicidad ascendieron en 1990 a 145168 millones.

En las televisiones privadas, Antena 3 se embolsó 5200 millones de pesetas en publicidad durante 1990. Las pérdidas asumidas por la cadena se cifraron en 5300 millones, 2300 millones menos de lo previsto. Según las estimaciones, de la cadena, 
los ingresos publicitarios debían ser de 13700 millones en 1991, mientras que el déficit se evaluaba en 3600 millones de pesetas.

El déficit de Tele 5 al cierre de su primer ejercicio llagaba a los 4000 millones de pesetas, cantidad inferior al gasto realizado en 3000 millones de pesetas. Para 1991, preveía beneficios publicitarios del orden de los 23700 millones de pesetas, que en 1992 se situarían en los 34000 millones.

Canal Plus declaraba en 1991 un déficit de 3.600 millones de pesetas. Los abonados eran 137.000 y la audiencia se cifraba en 540.000 personas (3,96 personas por descodificador).

En la radio, la publicidad creció un $225,7 \%$ en el período 1982.88. los ingresos publicitarios alcanzaron en 1988 los 60.250 millones de pesetas, con un incremento del $21,5 \%$, el menor de los observados en el resto de medios de comunicación, según el informe de Fundesco ${ }^{21}$ referido a ese año.

La cadena Ser, COPE y Antena 3, que concentraban el $64 \%$ de la audiencia, consiguieron beneficios récord en 1988. La SER incrementó sus resultados en 1987 en un $46,3 \%$ al contabilizar 1.569 millones de pesetas en publicidad. Al COPE, que aumentó sus ingresos publicitarios en un $28,8 \%$, tuvo 706 millones de ganancia, mientras que Antena 3, con 501 millones de pesetas, logró una mejora del 26\%. Un año después, las tres primeras cadenas privadas alcanzarían un fuerte incremento de sus ingresos en relación al 1988, al sumar cerca de 5.700 millones de pesetas por publicidad. Antena 3 aumentó sus ingresos un 186\% y obtuvo 1.410 millones de beneficio. La COPE superó sus resultados en un 81\% -2254 millones de pesetas-, y la SER, con un crecimiento del 37\%, contabilizó unos ingresos de 2.023 millones de pesetas.

\footnotetext{
${ }^{21}$ DIAZ NOSTY, Bernardo. "La radio en España: Entre la crisis de identidad y los grandes beneficios" en VV.AA. (1989) Comunicación social: Tendencias. Fundesco. Madrid (Pág.55 y ss.).
} 
En el año de la implantación de los tres canales de televisión privada, los recortes en el volumen de facturación publicitaria afectaron fundamentalmente a la radio. Según datos de JWT ${ }^{22}$ recogidos en el informe Fundesco ${ }^{23}$ relativo a 1990, los anunciantes invirtieron en la radio 79.000 millones de pesetas, un 9,7\% más que en 1989. Antena 3 volvió a ocupar la primera posición por los resultados conseguidos, con un aumento de más del $20 \%$ respecto al año anterior. La Cadena COPE registró un avance del $15 \%$, y la SER mejoró sus ingresos en un $4 \%$.

Este era. A grandes rasgos, el panorama mediático en nuestro país en los momentos previos y posteriores a la fusión entre Radio Nacional de España y Radio cadena española: es decir, el entorno mediático entre la década de los ochenta y noventa.

\footnotetext{
${ }^{22}$ Al igual que en otros medios, las estimaciones de JWT sobre facturación publicitaria no coinciden con los datos facilitados por las empresas de radiodifusión.

23 DIAZ NOSTY, Bernardo. "Radio: síntomas de recesión" en VV.AA. (1991): Comunicación social: Tendencias. Fundesco. Madrid (Pág. 80).
} 


\section{Bibliografía}

BEAUMONT, José F. (1990): “La batalla de la televisión privada” en VV.AA. (1990): Anuario El País 1990. Ediciones El País. Madrid.

BEAUMONT, José F. (1991): "La cuenta atrás del satélite Hispasat" en VV.AA. (1991): Anuario El País 1991. Ediciones El País. Madrid.

DIAZ NOSTY, Bernardo (1989): “Espacio autonómico audiovisual” en VV.AA. (1989): Comunicación Social 1989: Tendencias. Fundesco. Madrid.

DIAZ NOSTY, Bernardo. (1991): “La millonaria seducción del espectáculo” en VV.AA. (1991): Comunicación social: Tendencias. Fundesco. Madrid.

DIAZ-NOSTY, Bernardo. (1989): “La radio en España. Entre la crisis de identidad y los grandes beneficios" en VV.AA. (1989): Comunicación Social: Tendencias. Fundesco Madrid.

DIAZ NOSTY, Bernardo. (1991): “Radio: síntomas de recesión” en VV.AA. (1991): Comunicación social: Tendencias. Fundesco. Madrid.

DIAZ NOSTY, Bernardo (1990): “Nuevo mosaico audiovisual" en VV.AA. (1990): Comunicación Social: Tendencias. Fundesco. Madrid.

DIAZ NOSTY, Bernardo. (1991): “Televisión: la pobre pluralidad del espectáculo" en VV.AA. (1991): Comunicación Social: Tendencias. Fundesco. Madrid.

DIAZ-NOSTY, Bernardo. (1989): “La publicidad en el centro de la comunicación” en VV.AA. (1989): Comunicación Social: Tendencias. Fundesco. Madrid. 
LÓPEZ ESCOBAR, Esteban y DE LA VIUDA, Luis Ángel (19991): “La televisión no pública" en VV.AA (1990-91): Revista Situación 1990/91. Servicios de estudios del BBV. Madrid.

MANEIRO VILA, Arturo (1991): "Las televisiones autonómicas en España" en VV.AA (1990-91): Revista Situación 1990/91. Servicio de estudios del banco Bilbao-Vizcaya. Madrid.

MADINAVEITIA, Eduardo (1991): "Tendencias en medios audiovisuales" en VV.AA. (1991): Comunicación Social: Tendencias. Fundesco. Madrid.

ORIOL-COSTA, Pere (1986): La crisis de la televisión pública. Paidós Comunicación. Barcelona.

PÉREZ ORNIA, José Ramón (1998): "Más televisión" en VV.AA. (1988): “Anuario El País 1988". Ediciones El País. Madrid.

VV.AA. (1993): "La televisión defiende su trozo de tarta" en Noticias de la Comunicación. Publicaciones Profesionales no 93, 10/16 de mayo de 1993. Madrid. 